\title{
Residual Stress Generation during Laser Cladding of Steel with a Particulate Metal Matrix Composite**
}

\author{
By A. Plati, J. C. Tan, I. O. Golosnoy, R. Persoons, K. van Ackerand T. W. Clyne*
}

Laser cladding is used to coat and repair the surface of various components. A significant issue relating to optimisation of the process is the generation of residual stresses. These are affected by the high thermal gradients inherent in the process, and associated differential thermal contraction. These stresses can lead to various types of distortion. A customised 3-D finite element model has been developed, incorporating these effects, based on simulation of conductive, convective and radiative heat transfer, and assuming elastic-perfectly plastic deformation behaviour. Creep effects have been neglected and the cladding (particulate metal matrix composite) has been treated as a continuum. Comparisons are presented between measured and simulated thermal fields and specimen deflection histories. The results indicate that the main features of residual stress generation in this type of system have been captured in the model. Implications for process optimization and control are briefly discussed.

\section{Introduction}

In laser cladding, a laser beam is used to melt a powder stream as it is distributed onto the surface of a substrate. During this process, it is common for a thin layer at the surface of the substrate to be melted, facilitating the formation of a strong bond between cladding and substrate. The process is increasingly being employed in industry to coat and repair surfaces of components. The cladding material is commonly designed to increase resistance to wear, corrosion, erosion and oxidation. For example, there is interest in the use of (particle-reinforced) metal matrix composites (MMCs) for cladding, since these materials often exhibit excellent wear resistance characteristics. ${ }^{[1-4]}$ There has been extensive study recently ${ }^{[5-9]}$ of the tribological and mechanical properties of substrates after laser cladding with particulate MMCs.

There has also been extensive previous study of the laser processing of metals, covering the regimes of laser drilling and laser glazing, as well as laser surface melting. Finite element methods have been used previously ${ }^{[10-12]}$ to investigate residual stress development and associated distortion of the substrate during laser surface melting (without powder deposition). Other studies ${ }^{[13-17]}$ have been focused on microstructural changes during laser cladding, both in the heat affected zone of the substrate and in the deposited material.
There has, however, been relatively little study hitherto of thermo-mechanical effects arising during the laser cladding process itself. The present work is aimed at obtaining improved understanding of how residual stresses and associated distortions can arise during laser cladding.

\section{Experimental Procedures}

A $3 \mathrm{~kW} \mathrm{CO}$ laser was used to deposit MMC powder, comprising nickel reinforced with spherical particles of tung-

[*] A. Plati, Dr. J. C. Tan, Dr. I. O. Golosnoy, Prof. T. W. Clyne Department of Materials Science $\mathcal{E}$ Metallurgy,

Cambridge University,

Pembroke Street, Cambridge CB2 3 QZ, UK

E-mail: twc10@cam.ac.uk

Dr. K. van Acker, Dr. R. Persoons

Materials Technology Centre, VITO Flemish Institute for Technological Research Boeretang 200 B-2400 Mol, Belgium

[**] Financial support for this work has been received from the Belgian Federal government, via contract PA-67-281, from the EPSRC, via a Platform Grant, and from the Cambridge European Trust. 


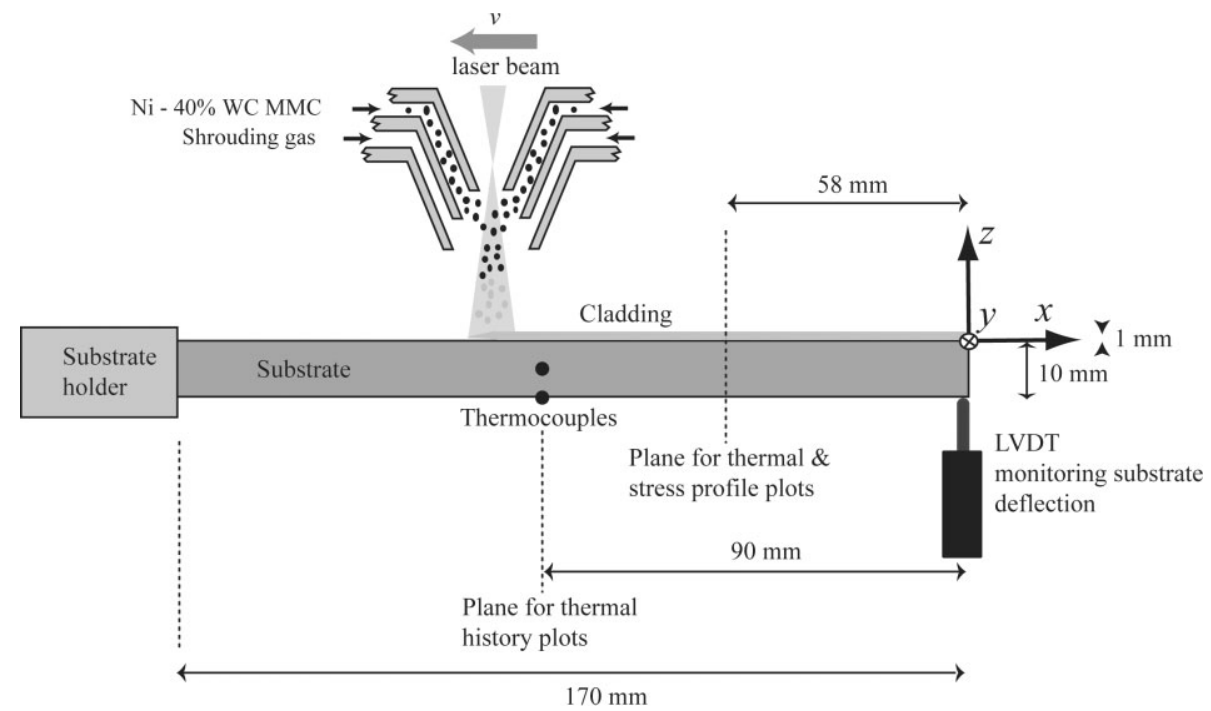

Fig. 1. Schematic representation of the experimental set-up during laser cladding.

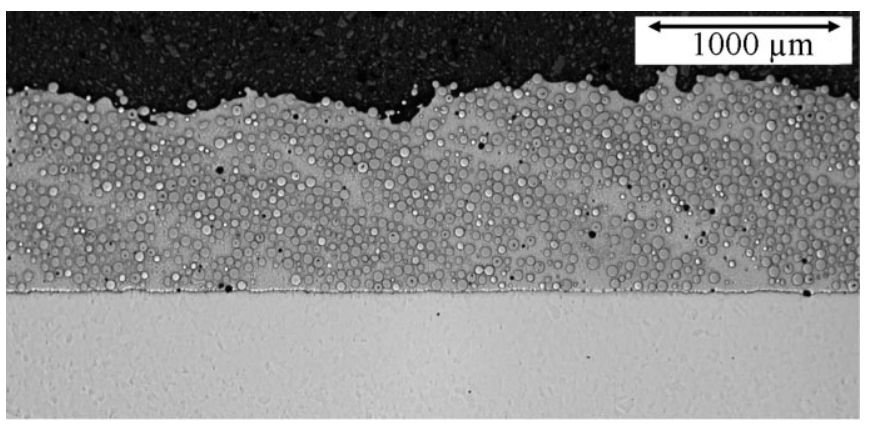

Fig. 2. SEM micrograph of an axial section through a Ni-40\%WC laser clad coating on a 304 stainless steel substrate.

sten carbide, on a 304 stainless steel substrate. The experimental set-up is shown in Figure 1. The volume fraction of ceramic in the MMC coating was about $40 \%$. A typical micrograph illustrating the microstructure of a laser clad coating of this type is shown in Figure 2. The powder feed rate during coating deposition was about $0.52 \mathrm{~g} \mathrm{~s}^{-1}$ and the velocity of the deposition head was about $12.5 \mathrm{~mm} \mathrm{~s}^{-1}$. The effective laser beam radius on the surface of the substrate was measured to be $0.17 \mathrm{~mm}$. In order to simplify the heat flow associated with the process, a relatively narrow substrate was employed (with insulating side-supports to contain the deposited powder), such that only a single pass was needed to deposit the cladding. One end of the substrate, which had a length, width and thickness of 170, 3.8 and $10 \mathrm{~mm}$ respectively, was bolted to a steel block - see Figure 1. The laser beam was switched on at the free end $\left(t=0 \mathrm{~s}, x_{\mathrm{c}}=0 \mathrm{~mm}, y_{\mathrm{c}}=0 \mathrm{~mm}\right)$ and then translated $\left(v=12.5 \mathrm{~mm} \mathrm{~s}^{-1}\right)$, towards the bolted end. The powder passed through the laser beam, absorbing heat, and was deposited onto the top surface of the substrate. The length of the laser-clad track was $110 \mathrm{~mm}$ and the thickness of the coating was approximately $1 \mathrm{~mm}$. The thermal history of the substrate was monitored via two thermocouples, positioned at the mid-section and on the back surface, $90 \mathrm{~mm}$ from the free end. Specimen bending was monitored using an LVDT (linear variable displacement transducer) to measure the vertical deflection at the free end - see Figure 1.

\section{Model Development}

Thermal and mechanical phenomena were decoupled in the analysis. In practice, any coupling between them is expected to be small. Results from the thermal analysis were used to calculate the stress and strain fields, and hence the specimen deflection history, which was compared with experimental data. It was assumed that any inter-penetration of the cladding and the substrate, which could arise if there were appreciable substrate melting, was in fact of negligible extent. It can be seen in Figure 2 that there was little or no obvious substrate melting. In general, the molten zone was observed to be less than about $50 \mu \mathrm{m}$ in thickness, making it of negligible significance in terms of its effect on the thermal field or the associated stresses and strains.

\subsection{Thermal Analysis}

The thermal analysis was performed first, using Abaqus 6.5.1. The substrate and the coating were both represented by 8-noded heat transfer elements. Vertical deflections of the substrate, while useful for strain field monitoring purposes, were not large enough to affect the laser focus conditions or the absorbed heat flux. The intensity distribution of the laser beam was assumed to be Gaussian, with radial symmetry, such that the heat flux at a radial distance $r$ from the beam axis is given by

$Q(r)=\frac{2 P_{\mathrm{as}}}{\pi r_{\mathrm{b}}^{2}} \exp \left[-2\left(\frac{r}{r_{\mathrm{b}}}\right)^{2}\right]$

where $P_{\mathrm{as}}$ is the total power absorbed by the substrate, $r_{\mathrm{b}}$ is the effective radius of the laser beam at the substrate surface, and the distance of a point $(x, y)$ from the beam axis $\left(x_{c}, y_{c}\right)$ is given by

$r=\left(\left(x-x_{\mathrm{c}}\right)^{2}+\left(y-y_{\mathrm{c}}\right)^{2}\right)^{1 / 2}$, in which $x_{\mathrm{c}}=-v t$ and $y_{\mathrm{c}}=0$

The total power of the laser beam, $P_{0}$, is partitioned into the following components

$P_{0}=P_{\mathrm{ap}}+P_{\mathrm{as}}+P_{\mathrm{rp}}+P_{\mathrm{rs}}=P_{0}\left(p_{\mathrm{ap}}+p_{\mathrm{as}}+p_{\mathrm{rp}}+p_{\mathrm{rs}}\right)$

where the subscripts $a$ and $r$ mean "absorbed" and "reflected", while $p$ and $s$ refer to "powder" and "substrate" 
Table 1. Properties of $\mathrm{Ni}-40 \% \mathrm{WC}$.

\begin{tabular}{llllll}
$\begin{array}{l}\text { Temperature, } \\
\mathrm{T}\left({ }^{\circ} \mathrm{C}\right)\end{array}$ & $\begin{array}{l}\text { Thermal } \\
\text { Conductivity } \\
\mathrm{K}\left(\mathrm{W} \mathrm{m}^{-1} \mathrm{~K}^{-1}\right)\end{array}$ & $\begin{array}{l}\text { Thermal } \\
\text { Expansivity } \\
\left(\text { microstrain } \mathrm{K}^{-1}\right)\end{array}$ & $\begin{array}{l}\text { Yield } \\
\text { Stress }^{\S}, \sigma_{\mathrm{Y}} \\
(\mathrm{MPa})\end{array}$ & $\begin{array}{l}\text { Young's } \\
\text { modulus }^{\dagger}, \mathrm{E} \\
(\mathrm{GPa})\end{array}$ & $\begin{array}{l}\text { Latent Heat } \\
{\text { of Fusion, } \Delta \mathrm{H}_{\mathrm{f}}}_{\mathrm{kJ} \mathrm{kg}^{-1}}\end{array}$ \\
\hline 25 & 65 & 12.0 & 199 & 307 & - \\
325 & 68 & 11.9 & 187 & -- & - \\
725 & 83 & 10.7 & 65 & -- & - \\
1455 & - & -- & -- & -- & 223
\end{tabular}

${ }^{\S}$ Calculated values obtained from data for matrix and reinforcement, using the Eshelby method [20] ${ }^{+}$Experimentally measured values

Table 2. Properties of 304 stainless steel. [21,22]

\begin{tabular}{|c|c|c|c|c|c|}
\hline $\begin{array}{l}\text { Temperature, } \\
\mathrm{T}\left({ }^{\circ} \mathrm{C}\right)\end{array}$ & $\begin{array}{l}\text { Thermal } \\
\text { Conductivity, } \\
\mathrm{K}\left(\mathrm{W} \mathrm{m}^{-1} \mathrm{~K}^{-1}\right)\end{array}$ & $\begin{array}{l}\text { Thermal } \\
\text { Expansivity, } a \\
\text { (microstrain } \mathrm{K}^{-1} \text { ) }\end{array}$ & $\begin{array}{l}\text { Yield } \\
\text { Stress }^{\S}, \sigma_{Y} \\
(\mathrm{MPa})\end{array}$ & $\begin{array}{l}\text { Young's } \\
\text { modulus, E } \\
(\mathrm{GPa})\end{array}$ & $\begin{array}{l}\text { Latent Heat } \\
\text { of Fusion, } \Delta \mathrm{H}_{\mathrm{f}} \\
\mathrm{kJ} \mathrm{kg}^{-1}\end{array}$ \\
\hline 25 & 14.8 & 16.9 & 241 & 193 & - \\
\hline 400 & 20.7 & 17.3 & 159 & - & - \\
\hline 600 & 23.5 & 18.4 & 134 & - & - \\
\hline 800 & 25.8 & 18.7 & 114 & - & - \\
\hline 1000 & 28.8 & - & 97 & - & - \\
\hline 1100 & 29.9 & - & - & - & - \\
\hline 1200 & 31.6 & - & 88 & - & - \\
\hline 1300 & 32.8 & 11.9 & 76 & - & - \\
\hline 1454 & - & - & - & - & 270 \\
\hline
\end{tabular}

(surface). The proportion of the injected power which went into melting the cladding powder, $p_{\mathrm{ap}}$, was taken as $10 \%$ of the initial energy of the laser beam. This energy raised the powder temperature from ambient to $\sim 1500{ }^{\circ} \mathrm{C}$ and liquified the Ni particles (ie supplied the necessary latent heat). The percentage of the incident laser power absorbed by the substrate $p_{\text {as, }}$ was taken as $30 \%$, based on published values for the energy distribution of $\mathrm{CO}_{2}$ laser beams. ${ }^{[18]}$ The proportion of total power reflected by powder and substrate was thus taken to be about $60 \% .{ }^{[18]}$ Other thermal boundary conditions covered radiative heat losses (via an emissivity of 0.3 ) and convective cooling (via a heat transfer coefficient of $25 \mathrm{~W}$ $\mathrm{m}^{-1} \mathrm{~K}^{-1}$ ) to an environment at $25^{\circ} \mathrm{C}$.

Build-up of the cladding was modeled using a volume element activation technique. ${ }^{[19]}$ All elements of the cladding were initially deactivated (absent for purposes of heat exchange and strain compatibility). The elements of the coating were activated as the heat source moved along the length of the substrate and the coating was deposited. Upon activation, the initial temperature of a cladding volume element was taken to be the melting temperature of $\mathrm{Ni}\left(1455^{\circ} \mathrm{C}\right)$. The $\mathrm{Ni}$ powder was thus assumed to be molten, with no superheat, while the WC particles remained solid and were also at this temperature. This incorporates the assumption that there was no reaction between the WC particles and the surrounding $\mathrm{Ni}$. In practice, some intermetallic was formed, but less than $5 \%$ of the WC was consumed in this way.

The reactivation of the cladding elements was followed by release of latent heat during solidification of the coating. After all of the cladding elements had been activated, external heat injection was discontinued, but the thermal analysis was continued until the system temperature approached ambient. During thermal analysis, thermal histories of all substrate and cladding elements were recorded, and subsequently used in the stress analysis. For both thermal and stress analyses, the temperature-dependence of substrate and cladding properties was taken into account. The temperature-dependent properties used for the coating and the substrate are presented in Table 1 and Table 2 respectively. Thermal histories from selected points in the substrate were compared with experimental data.

\subsection{Stress Analysis}

For the stress analysis, temperatures from the thermal elements were assigned to corresponding stress elements, using same element mesh. The 3-D elements used in this part of the analysis were 8-noded stress elements. In the through-thickness direction, there were two elements in the coating and six in the substrate. Deformation of both substrate and cladding was assumed to approximate to elastic-perfectly plastic behaviour, with temperature-dependent yield stresses, but no work hardening or other prior strain history effects. Creep (time-dependent deformation) was also neglected.

Perfect mechanical bonding was assumed between substrate and cladding, which is consistent with the fact that strong metallurgical bonds are normally formed during laser cladding, and the observed absence of significant interfacial porosity - see Figure 2. All 3-D elements in the cladding were taken to be activated throughout for purposes of stress analysis. This may sound unrealistic, but it should be borne in mind that, until they have started to cool below the melting temperature of $\mathrm{Ni}, 3-\mathrm{D}$ elements are taken to be stress-free (and hence effectively absent from a mechanical point of view). Since the substrate was attached at one end to a rigid fixture, it was treated as a cantilever beam. For both thermal and stress analyses, time increments were established auto- 
matically, using the largest values consistent with numerical convergence of iterations in the implicit solution scheme. The deflection history of the free end of the substrate was compared with experimental data.

\section{Modelling Results}

Comparisons between modelled and experimental data for thermal and deflection histories are shown in Figure 3. It can be seen that, in general, these comparisons indicate that the main features of the process have been captured. Figures 4 and 5 show temperature and stress fields after different times, together with plotted through-thickness distributions at a distance of $58 \mathrm{~mm}$ from the free end. It can be seen in Figure 4(a) that, as the laser beam passes, a thin layer of the substrate melts, and of course the cladding is also molten at this point. There are high thermal gradients present in the near surface regions of the substrate at this stage. The heated regions near the top surface of the substrate thus tend to expand (in the $x$-direction), but are constrained by the cooler regions in the lower parts. The net effect can be seen in Figure 5(a), which shows how the upper regions of the substrate are put under compressive stress, and also illustrates how the free end of the substrate thus tends to be deflected downwards (see also Fig. 3(b)). It may also be noted that, in order to maintain the
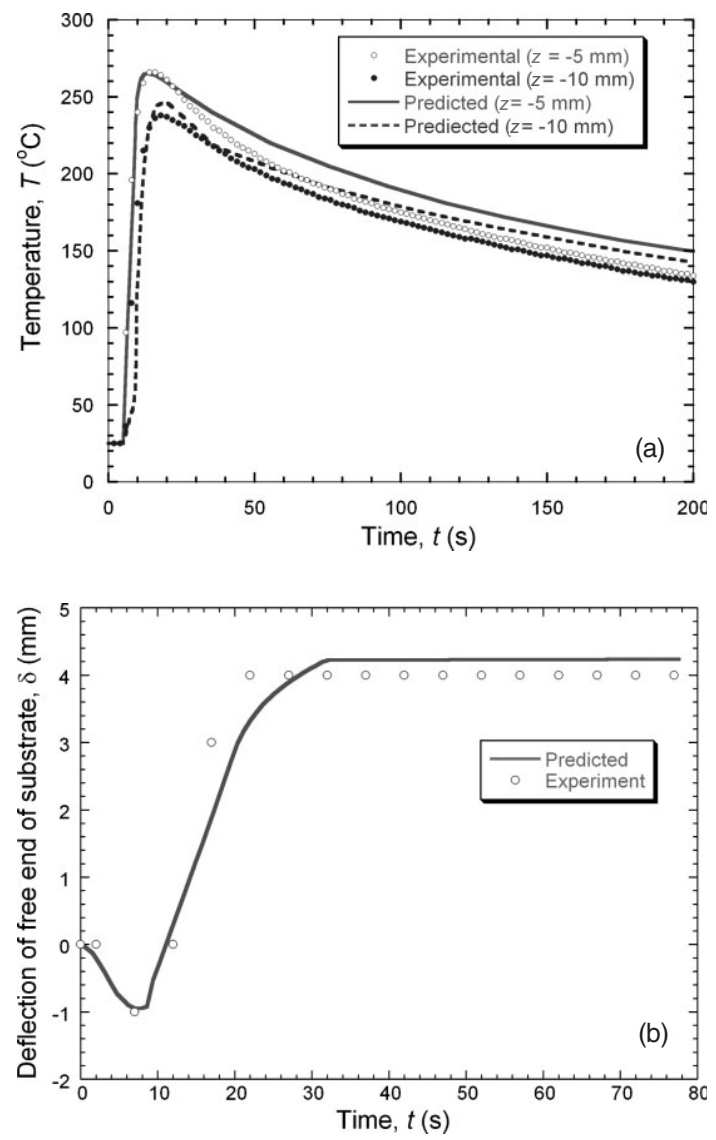

Fig. 3. Comparisons between predicted and measured data for a) thermal histories and b) deflection history, during cladding and subsequent cooling. necessary force and moment balances across any given section, the substrate regions near the lower surface are also put into compression, as the specimen adopts this curvature. The central regions of the substrate are at this stage under tensile stress, while the cladding, which is molten or close to the melting temperature, is effectively stress-free.

As the laser beam moves on, the sections it has passed become cooler and more uniform in temperature (Fig. 4(b)) and the stress profile also changes (Fig. 5(b)). The substrate yielding (in compression) which occurs at higher temperatures (when the yield stress is relatively low) leads to stress-free lengths in the $x$-direction becoming reduced in the the upper regions of the substrate. As these regions cool, they are therefore put into tension and the substrate starts to curve in the opposite direction (see also Fig. 3(b)). Force and moment balances must again operate and the net effect is that the lower regions of the substrate, which never became very hot and thus experienced little or no yielding, are now put into tension by the adoption of curvature, while the central regions end up in net compression. This process continues as the complete specimen becomes cold (Fig. 5(c)).

It may be noted that, since the coating is relatively thin, it contributes little to the force and moment balances, and the (relatively small) mismatch in thermal expansivity between substrate and coating is not very significant. However, the curvature adopted by the substrate, as a consequence of the extensive yielding near the top surface, does put the coating into substantial compression, which is retained as a residual stress. For the substrate, in contrast, both upper and lower surfaces are in residual tension in the cooled specimen (Fig. 5(c)). It may be noted that a rather similar distribution of residual stress in the substrate would result if the laser beam had been passed over it in the absence of any coating. Of course, it may be of practical significance (and perhaps beneficial) that the cladding is under residual compression, although it should be noted that the situation may be more complex during cladding of a real component, in which multi-axial stresses might develop and there could be substantial constraint of various types, inhibiting the development of curvature.

\section{Conclusions}

The following conclusions can be drawn from this work.

(a) A simple experimental set-up has been used to study the laser cladding process. A long, narrow substrate shape was used, clamped at one end, with an MMC powder being progressively deposited along part of its length, starting at the free end. A 3-D numerical finite element model was employed to simulate the associated heat flow and mechanical deformation. Comparisons have been made between measured and predicted thermal and specimen deflection histories. This specimen shape allowed attention to be focussed on the effects occurring during a single pass of the laser beam, primarily as a consequence of heat flow parallel to the direction of beam motion and in the through-thickness direc- 


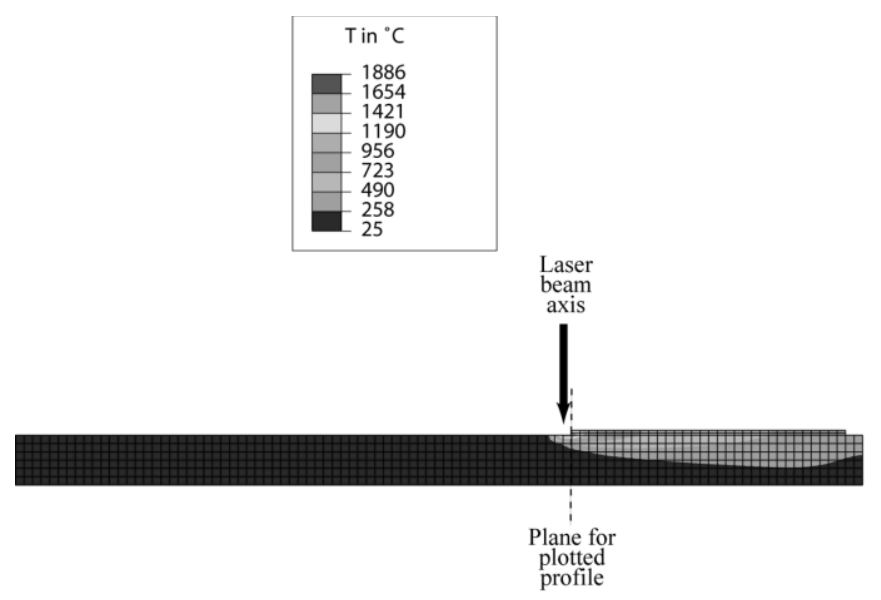

(a)
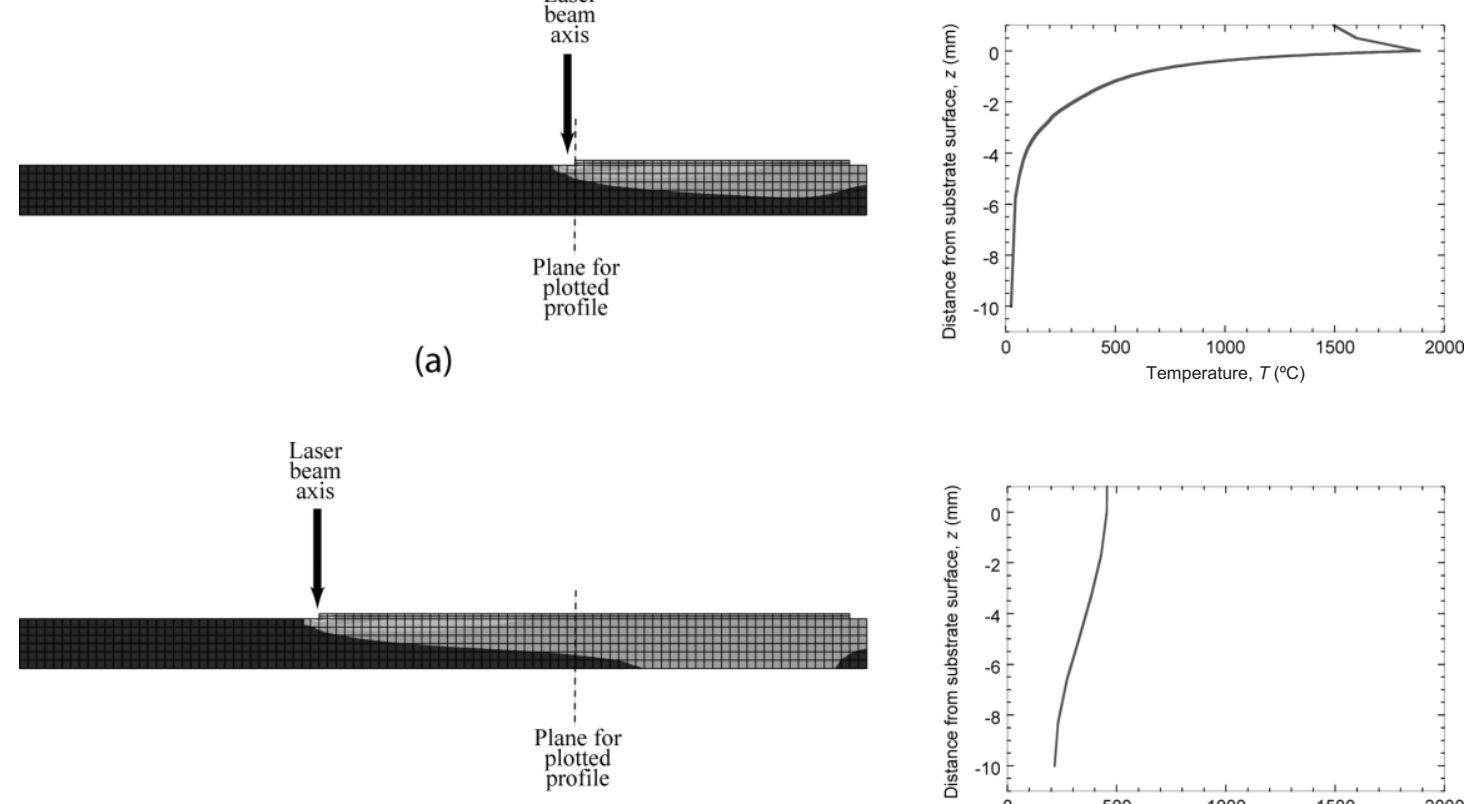

(b)

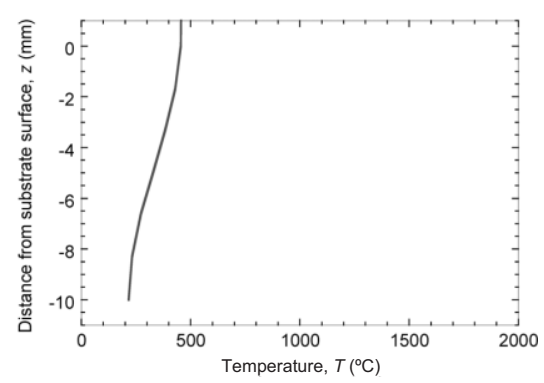

Fig. 4. Predicted $T(x, z)$ thermal fields and through-thickness temperature profiles at a selected plane $(x=-58 \mathrm{~mm})$, after times of (a) $5 \mathrm{~s}$ and (b) $9 \mathrm{~s}$.

tion. Typical laser beam translation velocities are sufficiently high to ensure that the motion has a strong influence on the nature of the thermal field.

(b) During laser cladding, high thermal gradients tend to develop in the through-thickness direction. The associated differential thermal contraction often generates relatively high stresses, which are likely to cause yielding in the hot, near-surface regions. This plastic deformation leads to the generation of residual stresses and also tends to cause residual distortion of the work-piece. The specimen underwent changes in curvature during the process and these were in good agreement with predictions from the model, as were the observed thermal histories. It is therefore clear that the main thermo-mechanical features of the process have been captured in the model, which could be used to predict and control stress generation and distortion during laser cladding of shaped components.

(c) The deposition of the coating, which in the present work was a Ni-based MMC, actually has relatively little effect on these thermomechanical phenomena occurring in the substrate, or on the residual stresses. This is unsurprising, partly because the coating is relatively thin and partly because much of the injected heat from the laser beam goes directly into the substrate, with only a relatively small proportion being first absorbed by the coating powder as it is deposited onto the substrate surface. However, there is a tendency for the clad- ding layer to be left under substantial residual stress at the end of the process, particularly if the substrate is able to adopt curvature (distort). For the conditions of these experiments, the cladding was left in residual compression, and this is likely to be the case under a wide range of conditions.

Received: February 01, 2006

[1] E. Kilickap, O. Cakir, M. Aksoy, A. Inan, J. Mater. Proc. Techn. 2005, 164, 862.

[2] D. Roy, B. Basu, A. B. Mallick, Intermetallics 2005, 13, 733.

[3] K. M. Shorowordi, A. S. M. Haseeb, J. P. Celis, Wear 2004, 256, 1176.

[4] H. Berns, Wear 2003, 254, 47.

[5] L. Dubourg, D. Ursescu, F. Hlawka, A. Cornet, Wear 2005, 258, 1745.

[6] W. Pang, H. C. Man, T. M. Yue, Mat. Sci. Eng. A 2005, 390, 144.

[7] D. Galvan, V. Ocelik, Y. Pei, B. J. Kooi, J. T. De Hosson, E. Ramous, J. Mats. Eng. Performance 2004, 13, 406.

[8] H. C. Man, Y. Q. Yang, W. B. Lee, Surf. Coat. Technol. 2004, 185, 74.

[9] A. Yakovlev, P. Bertrand, I. Smurov, Thin Solid Films, 2004, 453, 133.

[10] B. Taljat, B. Radhakrishnan, T. Zacharia, Mater. Sci. Eng. A 1998, 45, 246. 


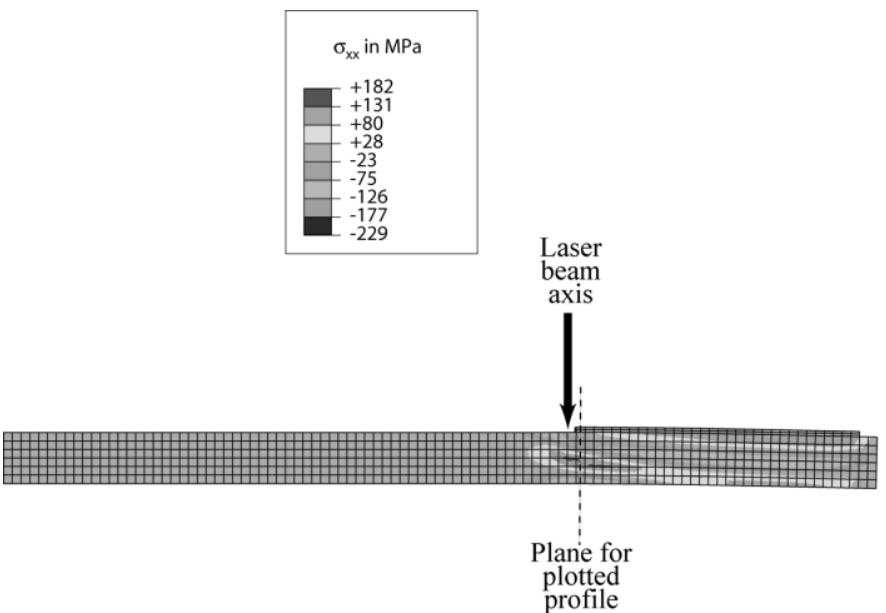

(a)
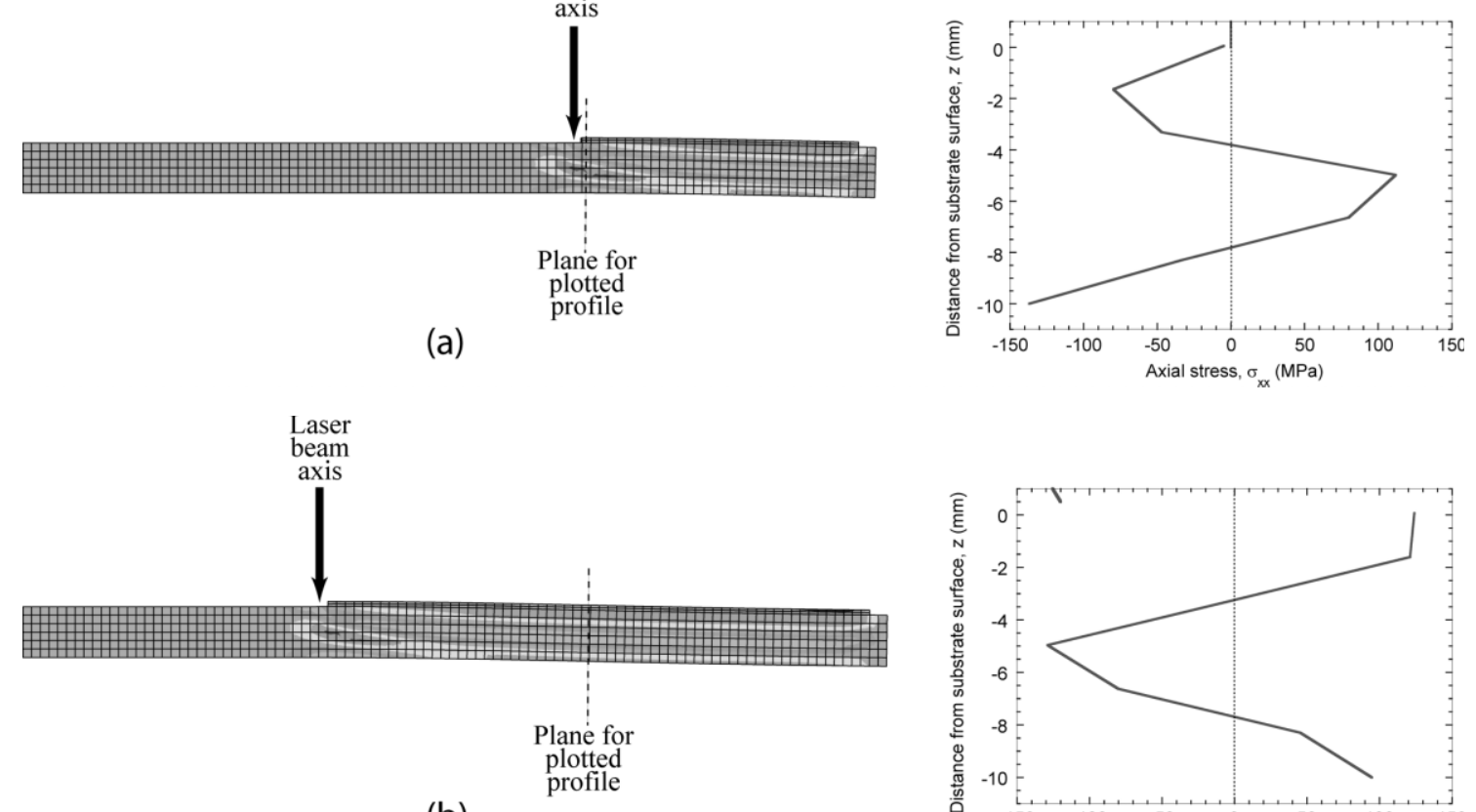

(b)
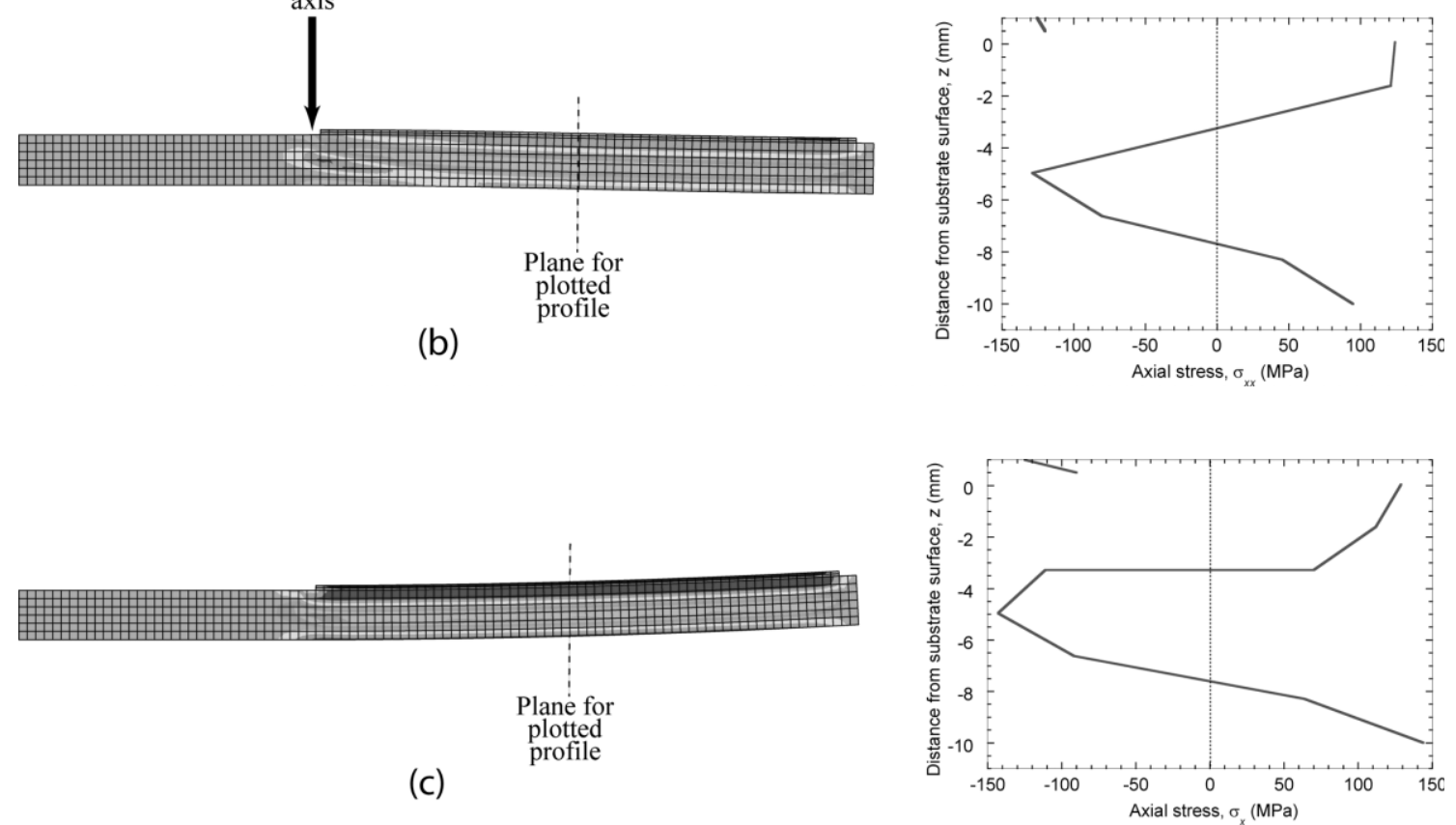

Fig. 5. Predicted $\sigma_{x x}(\chi, z)$ axial stress fields and through-thickness stress profiles at a selected plane $(\chi=-58 \mathrm{~mm})$, after times of (a) $5 \mathrm{~s}$, (b) $9 \mathrm{~s}$ and (c) $2000 \mathrm{~s}$.

[11] G. Chen, S. Xu, C. C. Poon, A. C. Tam, J. Appl. Mech. Trans. ASME 1999, 66, 772.

[12] M. Reeves, A. J. Moore, D. P. Hand, J. D. C. Jones, J. R. Cho, R. C. Reed, S. P. Edwardson, G. Dearden, P. French, K. G. Watkins, Proc. Inst. Mech. Eng. B - J. Eng Manuf. 2003, 217, 1685.

[13] A. F. A. Hoadley, M. Rappaz, M. Zimmermann, Metall. Trans. B - Process Metall. 1991, 22, 101.

[14] A. Kar, J. Mazumder, J. Appl. Phys. 1987, 61, 2645.

[15] E. Toyserkani, A. Khajepour, S. Corbin, J. Laser Appl. 2003, 15, 153.

[16] A. J. Pinkerton, L. Li, Proc. Inst. Mech. Eng. C.-J. Mech. Eng. Sci. 2004, 218, 531.
[17] L. Han, F. W. Liou, K. M. Phatak, Metall. Mater. Trans. B. 2004, 35, 1139.

[18] H. Gedda, J. Powell, G. Wahlstrom, W-B. Li, H. Engstrom, C. Magnusson, J. Laser Appl. 2002, 14, 78.

[19] F. Z. I. Fanous, M. Y. A. Younan, A. S. Wifi, J. Pressure Vessel Technol. - Trans. ASME. 2003, 125, 144.

[20] T. W. Clyne, P. J. Withers, 1993, Cambridge Univ. Press, Cambridge. An Introduction to Metal Matrix Composites.

[21] K. C. Mills, 2002, Woodhead Publ. Ltd., UK. Recommended Values of Thermophysical Properties for Selected Commercial Alloys.

[22] ASM, Metals Handbook, American Society of Metals, Materials Park, Ohio 1990. 